\title{
Factors associated with uncontrolled hypertension and cardiovascular risk in hypertensive 60-year-old men and women-a population-based study
}

\author{
Axel C Carlsson', Per E Wändell ${ }^{1}$, Gunilla Journath ${ }^{2,3}$, Ulf de Faire ${ }^{4,5}$ and Mai-Lis Hellénius ${ }^{2}$
}

The objective of this study was to describe cardiovascular risk profiles of 60 -year-olds with uncontrolled diagnosed hypertension $(\geqslant 140 / 90 \mathrm{~mm} \mathrm{Hg}$ ) in comparison with individuals with controlled diagnosed hypertension. To study how medical, lifestyle and socioeconomic factors are associated with uncontrolled diagnosed hypertension in men and women separately, a populationbased, cross-sectional study of 4228 60-year-olds in Sweden, of whom 503 men and 445 women had previously diagnosed hypertension, was conducted. Physical examination including measuring blood pressure was carried out, and a medical/lifestyle/ socioeconomic questionnaire was completed. Only $22 \%$ of the men and $33 \%$ of the women with diagnosed hypertension had a blood pressure below $140 / 90 \mathrm{~mm} \mathrm{Hg}$. Both men and women had multiple cardiovascular risk factors in addition to hypertension. Antihypertensive monotherapy was more common in men and women with controlled hypertension. None of the participants without pharmacological treatment had a controlled blood pressure. Four factors were independently associated with uncontrolled hypertension in men: waist circumference above $97 \mathrm{~cm}$ (odds ratio $(O R)=1.85$, confidence interval $(\mathrm{Cl})=1.17-2.92)$, coronary heart disease $(\mathrm{CHD})(\mathrm{OR}=0.28, \mathrm{Cl}=0.17-0.46)$, no health care for financial reasons $(\mathrm{OR}=2.71, \mathrm{Cl}=1.09-6.78)$ and daily intake of fruit $(\mathrm{OR}=0.59, \mathrm{Cl}=0.37-0.93)$. In women, three factors remained independently associated: waist circumference above $78 \mathrm{~cm}(\mathrm{OR}=1.93, \mathrm{Cl}=1.09-3.43), \mathrm{CHD}(\mathrm{OR}=0.36, \mathrm{Cl}=0.18-0.72)$ and living in an apartment $(\mathrm{OR}=0.55, \mathrm{Cl}=0.35-0.85)$. More efforts are warranted to reduce blood pressure and to modulate associated risk factors to be able to reduce the high morbidity and mortality observed in individuals with hypertension. Hypertension Research (2009) 32, 780-785; doi:10.1038/hr.2009.94; published online 26 June 2009

Keywords: antihypertensive therapy; cardiovascular risk factors; education; hypertension control; lifestyle

\section{INTRODUCTION}

Hypertension is a major risk factor for cardiovascular diseases. ${ }^{1}$ Antihypertensive treatment has been shown to reduce the occurrence of total major cardiovascular events, and the larger the reduction of blood pressure that is achieved, the larger is the reduction in mortality and cardiovascular events is observed. ${ }^{2}$ Despite this established knowledge and benefits of blood pressure reductions, many hypertensive patients do not reach the goal for blood pressure reduction (below $140 / 90 \mathrm{~mm} \mathrm{Hg}) .^{3-6}$

A recent study reported different factors associated with newly diagnosed high blood pressure in men and women. ${ }^{7}$ Risk profiles, lifestyles and metabolic characteristics differed in men and women with normal and newly diagnosed high blood pressure. Cardiovascular risk profile in men and women with hypertension is highly important, as the risk of serious cardiovascular events is higher when additional cardiovascular risk factors are present. ${ }^{1}$ A study of hypertensive Americans showed that women have more cardiovascular risk factors than men. ${ }^{8}$ Contrasting these findings, men have two- to three-fold higher morbidity and mortality than do women, when treated for hypertension in Sweden. ${ }^{9}$

Uncontrolled blood pressure has been shown to be more common in individuals with more metabolic risk factors and is associated with metabolic syndrome. ${ }^{10}$ Other factors that have a role in achieving control of hypertension have not been addressed previously to the best of our knowledge. Factors that may be changed by lifestyle, if found, could be of help to healthcare professionals when giving advice to hypertensive patients. Factors that are not easily changed may give a hint that certain patients need more aggressive antihypertensive drug therapy to lower their blood pressure. The primary aim of this study was to describe the cardiovascular risk factor profile of hypertensive 60-year-old men and women in Stockholm County. The secondary aim was to search for lifestyle and socioeconomic factors associated with uncontrolled hypertension.

${ }^{1}$ Department of Neurobiology, Care Sciences and Society, Center for Family and Community Medicine, Karolinska Institutet, Huddinge, Sweden; ${ }^{2}$ Department of Medicine, Clinical Epidemiology Unit, Karolinska Institutet and Karolinska University Hospital Solna, Stockholm, Sweden; ${ }^{3}$ Merck Merck, Sharp and Dohme (Sweden) AB, Sollentuna, Sweden; ${ }^{4}$ Division of Cardiovascular Epidemiology, Institute of Environmental Medicine, Karolinska Institutet, Stockholm, Sweden; and ${ }^{5}$ Department of Cardiology, Karolinska University Hospital Solna, Stockholm, Sweden

Correspondence: AC Carlsson, Center of Family and Community Medicine, Karolinska Institutet, Alfred Nobels alle 12, 5th Floor, SE-141 83 Stockholm, Sweden.

E-mail: axelcefam@hotmail.com

Received 7 April 2009; revised 12 May 2009; accepted 1 June 2009; published online 26 June 2009 


\section{METHODS}

A study of 60-year-old men and women in Stockholm County

Every third man and woman in Stockholm County born within a 1-year period between 1937 and 1938 was invited to participate in a thorough healthscreening study from August 1997 to March 1999, that is, when they had reached the age of 60 years. The random sample was obtained from a register of the population in Sweden. The participants underwent a physical examination, with height, weight and waist circumference measurements being determined.

Fasting blood samples were collected for analysis and a comprehensive questionnaire with medical, lifestyle and socioeconomic questions was completed. Detailed method descriptions of the study have been published in previous studies of this cohort. ${ }^{711-13}$ The study was approved by the ethics committee at the Karolinska Institutet and all participants gave their written consent.

\section{Participants}

Out of the 5460 invited individuals, 4228 (77\%) participated, out of whom 2036 were men (73\% response rate) and 2192 were women (82\% response rate). Previously diagnosed hypertension was reported by 503 men and by 445 women, and they were included in this study (see Figure 1). A total of $85 \%$ of the participants with known hypertension were taking drugs for their hypertension.

\section{Blood pressure and uncontrolled hypertension}

Blood pressure was measured twice in the sitting position, after a 5-min rest, and the mean of the measurements was calculated. An automatic device was used (HEM 711, Omron Healthcare, Bannockburn, IL, USA). In participants with an upper arm circumference above $32 \mathrm{~cm}$, a wider cuff was used.

Previously known hypertension was reported in the questionnaire. Uncontrolled hypertension was defined as previously known hypertension, as reported in a questionnaire, with or without treatment and with systolic and/or diastolic blood pressure $\geqslant 140 / 90 \mathrm{~mm} \mathrm{Hg}$ measured on one occasion.

\section{Medical history and waist measurements}

History of coronary heart disease (CHD) (previous myocardial infarction or angina pectoris), hospitalizations, regularly consumed drugs and occurrence of cardiovascular symptoms were elicited in a questionnaire. The NCEP ATP III definition of the metabolic syndrome was used. ${ }^{14}$

Waist circumference was divided into quartiles and the relationship with uncontrolled hypertension was analyzed. On the basis of this preliminary analysis, we decided to dichotomize waist circumference in men at the median $(97 \mathrm{~cm})$ and at quartile 1 in women $(78 \mathrm{~cm})$ in the logistic regression models.

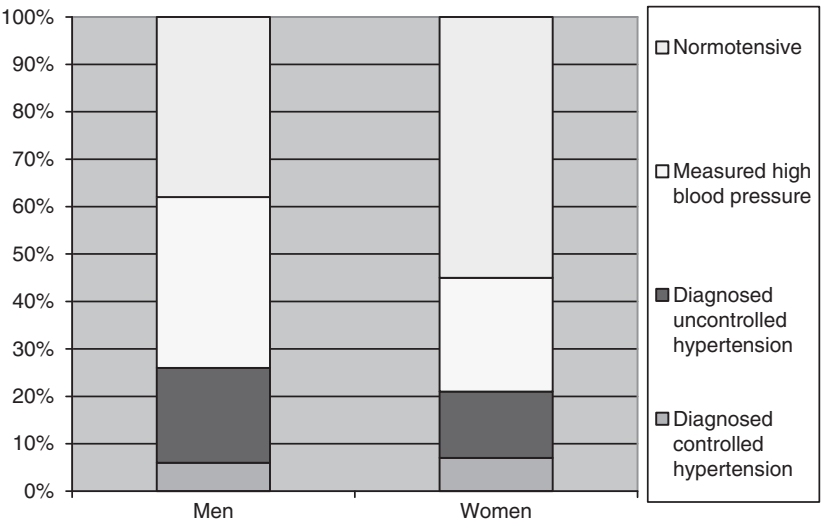

Figure 1 Hypertension prevalence and control in Sweden. The figure shows the percentage of 60-year-olds with a blood pressure $<140 /$ $90 \mathrm{~mm} \mathrm{Hg}$ (Normotensive), a blood pressure $\geqslant 140 / 90 \mathrm{~mm} \mathrm{Hg}$ and no previous diagnosis (Measured high blood pressure), diagnosed hypertension and a blood pressure $\geqslant 140 / 90 \mathrm{~mm} \mathrm{Hg}$ (Diagnosed uncontrolled hypertension) and diagnosed hypertension and a blood pressure $<140 /$ $90 \mathrm{~mm} \mathrm{Hg}$ (Diagnosed controlled hypertension).

\section{Lifestyle and socioeconomic factors}

Civil status was defined as married/living together (yes/no). An employment variable was defined according to working status (yes, full time or part-time/ no). Education level was defined as university, 12-year school and lower or no education. Living standard was defined as living in an apartment (yes/no) (compared with living in a house). Financial satisfaction was rated on a scale from 1 to 7 , with 1 being very bad and 7 being 'could not be better.' Answers 5-7 were defined as financially satisfied. Although health care is heavily subsidized in Sweden, a small fee is collected for each visit, up to 900 SEK (Swedish Kroner) (US\$110) annually. Dental care is not subsidized to the same extent. No health care for financial reasons was defined as having refrained from health care or dental care within the past year on one or more occasions. Smoking was coded as never smoked, former smoker or current smoker. High alcohol intake was estimated from questionnaires by intake in grams of pure alcohol per day, no alcoholic intake or up to $30 \mathrm{vs}$. $>30 \mathrm{~g}$ per day. The dietary intake of fruit, vegetables, fish, eggs, fried potatoes and sausage/bacon was measured using key nutritional questions.

\section{Blood analyses}

Cholesterol and triglycerides were analyzed using enzymatic methods (Bayer Diagnostics, Tarrytown, NY, USA). High-density lipoprotein (HDL)-cholesterol was measured enzymatically after the isolation of low-density lipoprotein (LDL) and very-LDL (VLDL) (Boehringer Mannheim GmbH, Mannheim, Germany), and LDL-cholesterol was estimated using Friedewald's method. Apolipoproteins, ApoB and ApoA-I, were measured by an immunoturbidimetric method. All blood samples were analyzed at the Calab Laboratory, Stockholm, Sweden.

\section{Blood lipids}

The cutoff levels used were the following: for total cholesterol, $<5 \mathrm{mmmoll}^{-1}$; for HDL, $<0.9 \mathrm{mmmoll}^{-1}$ and for LDL $<3.5 \mathrm{mmmoll}^{-1}$, as well as a triglyceride level of $<2.3 \mathrm{mmmoll}^{-1}$ (1997 therapy recommendations in Sweden, Apoteket 1997 (Stockholm, Sweden)). We also used the apolipoprotein ratio, ApoB/ApoA-I, to estimate cardiovascular risk. ${ }^{15}$ Low risk for men was defined as ApoB/ApoA-I $<0.7$, medium risk was $0.7-0.9$ and high risk was $>0.9$. For women, low risk was $<0.6$, medium risk was $0.6-0.8$ and high risk was $>0.8$.

\section{Statistical methods}

Calculations of statistical significance were carried out by the $\chi^{2}$-analysis or $t$-test. All tests were two-tailed, and the significance level was set at $P<0.01$ to reduce the risk of false positives due to multiple assessments of the data, except in multivariate logistic regression, in which the significance level was set at $P<0.05$. Trends (defined as $P=0.01-0.10$ ) and significant findings were tested in logistic regression models to find independent factors. The treatment variables, antihypertensive treatment and antihypertensive monotherapy, although significant, were not carried forward as the results are self-evident and may influence the logistic regression models to a great extent. We also tested all trends and significant variables in additional models with both men and women to find gender interactions (not presented in a separate table). Variables with a significant gender interaction are marked with an asterisk ${ }^{*}$ ) in Tables 1 and 2 .

We also tried to exclude known diabetics, participants with CHD and participants on lipid-lowering drugs in logistic regression models. This did not lead to additional findings.

$P$-values for Pearson's $\chi^{2}$-test of fit for optimized multivariate models were 0.55 for men and 0.94 for women, where a fit above 0.10 is acceptable.

All calculations were carried out using the computer program STATA 9.2 (StataCorp LP, College Station, TX, USA).

\section{RESULTS}

Blood lipid-lowering drugs were taken by $14 \%$ of the women and by $25 \%$ of the men with a controlled blood pressure. For individuals with an uncontrolled blood pressure, $6 \%$ of the women and $14 \%$ of the men were taking blood lipid-lowering drugs. Oral antidiabetic tablets 
Table 1 Univariate and multivariate logistic regression of factors possibly associated with uncontrolled hypertension in men

\begin{tabular}{lcc}
\hline Logistic regression models for men & Univariate models & $\begin{array}{c}\text { Optimized multivariate } \\
\text { model }\end{array}$ \\
\hline Variable & OR $(95 \% \mathrm{Cl})$ & OR $(95 \% \mathrm{Cl})$ \\
Waist circumference $>97 \mathrm{~cm}$ & $1.69(1.10-2.60)$ & $1.85(1.17-2.92)$ \\
CHD & $0.33(0.21-0.52)$ & $0.28(0.17-0.46)$ \\
Diabetes & $2.10(1.10-4.02)$ & - \\
Financially satisfied & $0.63(0.38-1.06)$ & - \\
No health care for financial reasons & $2.78(0.95-5.49)^{*}$ & $2.71(1.09-6.78)$ \\
High alcohol intake & $1.61(0.91-2.85)$ & - \\
(>30 vs. O-30g per day) & & - \\
Weekly intake of sausage or bacon & $1.33(1.01-2.42)^{*}$ & - \\
Daily intake of fruit & $0.60(0.39-0.93)$ & $0.59(0.37-0.93)$ \\
Goodness of fit, $\chi^{2}$ & - & 0.55 \\
\hline
\end{tabular}

Abbreviations: $\mathrm{CHD}$, coronary heart disease; $\mathrm{Cl}$, confidence interval; OR, odds ratio. *Denotes a significant interaction with gender: 'no health care for financial reasons "*'gender' $(\mathrm{OR}=0.29, \mathrm{Cl}=0.10-0.81)$, indicating that this is associated with uncontrolled hypertension in men but not women; 'weekly intake of sausage or bacon '*'gender' $(\mathrm{OR}=0.43, \mathrm{Cl}=0.24-0.79)$, indicating a significant association in men but not in women.

were taken by $3 \%$ of the women, and by $3 \%$ of the men with controlled hypertension and by $8 \%$ of the men with uncontrolled hypertension (data not shown in table).

Characteristics of hypertensive men and women with normal blood pressure or uncontrolled hypertension are presented in Table 3. In total, $22 \%$ of the men and $33 \%$ of the women had controlled hypertension $(<140 / 90 \mathrm{~mm} \mathrm{Hg})$. The average waist circumference was high in both men and women and was significantly higher in men with uncontrolled blood pressure $(102 v s .99 \mathrm{~cm})$. The average blood pressure was $160 / 97$ and $161 / 92 \mathrm{~mm} \mathrm{Hg}$ in men and women with uncontrolled blood pressure, respectively. Blood lipid disturbances were very common, and $\sim 30 \%$ of the individuals with diagnosed hypertension had, on the basis of their apolipoprotein ratio, a high cardiovascular risk. More than $40 \%$ of both men and women with diagnosed hypertension had metabolic syndrome. CHD was more common in individuals with a goal blood pressure. All men and women with controlled hypertension had antihypertensive therapy. Antihypertensive monotherapy was more common in both men and women with controlled hypertension.

Table 4 shows socioeconomic and lifestyle factors in men and women. More women living in an apartment compared with women living in a house had controlled hypertension. Apart from that, no significant differences were found.

Logistic regression models of factors from Tables 3 and 4 and their association with uncontrolled hypertension in men are shown in Table 1. Four variables remained significantly associated with uncontrolled hypertension in the optimized multivariate model for men. Waist circumference above $97 \mathrm{~cm}$ (odds ratio $(\mathrm{OR})=1.85$, confidence interval $(\mathrm{CI})=1.17-2.92)$ and no health care for financial reasons $(\mathrm{OR}=2.71, \quad \mathrm{CI}=1.09-6.78)$ were positively associated. CHD $(\mathrm{OR}=0.28, \mathrm{CI}=0.17-0.46)$ and daily intake of fruit $(\mathrm{OR}=0.59$, $\mathrm{CI}=0.37-0.93)$ were negatively associated with uncontrolled blood pressure. Logistic regression models in women are presented in Table 2. Three factors remained significantly associated in the optimized multivariate model. A waist circumference of above $78 \mathrm{~cm}$ was positively associated with uncontrolled hypertension $(\mathrm{OR}=1.93$, $\mathrm{CI}=1.09-3.43)$. $\mathrm{CHD}(\mathrm{OR}=0.36, \mathrm{CI}=0.18-0.72)$ and living in an apartment $(\mathrm{OR}=0.55, \mathrm{CI}=0.35-0.85)$ were negatively associated with uncontrolled blood pressure.
Table 2 Univariate and multivariate logistic regression of factors possibly associated with uncontrolled hypertension in women

\begin{tabular}{lcc}
\hline Logistic regression models for women & $\begin{array}{c}\text { Univariate } \\
\text { models }\end{array}$ & $\begin{array}{c}\text { Optimized } \\
\text { multivariate model }\end{array}$ \\
\hline Variable & OR $(95 \% \mathrm{Cl})$ & OR $(95 \% \mathrm{Cl})$ \\
Waist circumference $>78 \mathrm{~cm}$ & $1.95(1.12-3.38)$ & $1.93(1.09-3.43)$ \\
CHD & $0.45(0.24-0.85)$ & $0.42(0.22-0.81)$ \\
Employment & $1.59(1.05-2.32)$ & - \\
Living in apartment & $0.58(0.37-0.89)^{*}$ & $0.57(0.37-0.89)$ \\
Weekly intake of bacon or sausages & $0.68(0.45-1.02)^{*}$ & - \\
Daily intake of vegetables & $1.54(1.02-2.36)^{*}$ & - \\
Goodness of fit, $\chi^{2}$ & - & 0.94
\end{tabular}

Abbreviations: $\mathrm{CHD}$, coronary heart disease; $\mathrm{Cl}$, confidence interval; OR, odds ratio. *Denotes a significant interaction with gender: 'daily intake of vegetables '*'gender' $(\mathrm{OR}=1.85, \mathrm{Cl}=1.01-3.93)$, indicating that there was an association in women but not in men; 'living in an apartment '*'gender' $(\mathrm{OR}=0.47, \mathrm{Cl}=0.58-0.86)$ was associated with uncontrolled blood pressure in women but not in men.

Four significant $(P<0.05)$ multiplicative interaction terms with gender were found in univariate models of all participants (denoted by an asterisk $\left(^{*}\right)$ in Tables 1 and 2): 'no health care for financial reasons '*'gender' ( $\mathrm{OR}=0.29, \mathrm{CI}=0.10-0.81)$, indicating that this is associated with uncontrolled hypertension in men but not women; 'daily intake of vegetables '^'gender' $(\mathrm{OR}=1.85, \mathrm{CI}=1.01-3.93)$, indicating that there was an association in women but not in men; 'weekly intake of sausage or bacon ' 'gender' $(\mathrm{OR}=0.43, \mathrm{CI}=0.24-0.79)$, indicating a significant association in men but not in women; and finally, 'living in an apartment '*' gender' $(\mathrm{OR}=0.47, \mathrm{CI}=0.58-0.86)$ was associated with uncontrolled blood pressure in women but not in men.

\section{DISCUSSION}

Both men and women had multiple cardiovascular risk factors apart from hypertension. More than $40 \%$ of the participants with high blood pressure had metabolic syndrome, which is more prevalent compared with that in previous studies of the whole population of 60year-olds. ${ }^{12}$ In a large prospective study, the ApoB/ApoA-I ratio has been shown to correlate well with myocardial infarction risk in the INTERHEART study, ${ }^{16}$ and with death due to $\mathrm{CHD} .{ }^{17}$ A majority of the hypertensive participants in this study had high or medium high cardiovascular risk on the basis of their apolipoprotein levels. ${ }^{15}$

Only $22 \%$ of the men and $33 \%$ of the women with hypertension had blood pressure below $140 / 90 \mathrm{~mm} \mathrm{Hg}$, which makes the prevalence of hypertension in this cohort seem even worse (Figure 1). ${ }^{11}$ As people with metabolic syndrome and diabetes have an increased risk of cardiovascular disease, many of the participants would benefit from an even lower blood pressure as suggested in the present European guidelines (130/ $80 \mathrm{~mm} \mathrm{Hg}) .{ }^{1}$ These proportions of patients with controlled hypertension, although alarming, seem better than those previously reported in another Swedish study, in which only $15 \%$ had controlled hypertension. ${ }^{18}$ Better control of hypertension in women contrasts with an American study in which this was instead seen in men. ${ }^{19}$ Different factors were important for hypertension control in men and women and four gender interactions were found, adding to the bulk of evidence of sex differences in hypertension. ${ }^{7,9,20,21}$ Gender differences are common in cardiovascular medicine, which has, for example, led to separate Framingham 10-year risk equations in men and women. ${ }^{22} \mathrm{~A}$ part of the differences may be explained by the different sex hormones.

Living in an apartment was associated with better hypertension control in women, although it is often regarded as a marker of low socioeconomic status. This finding is puzzling and we have no explanation for this. 
Table 3 Medical and metabolic characteristics; differences between participants with controlled hypertension and participants with uncontrolled hypertension, in men and women with diagnosed hypertension

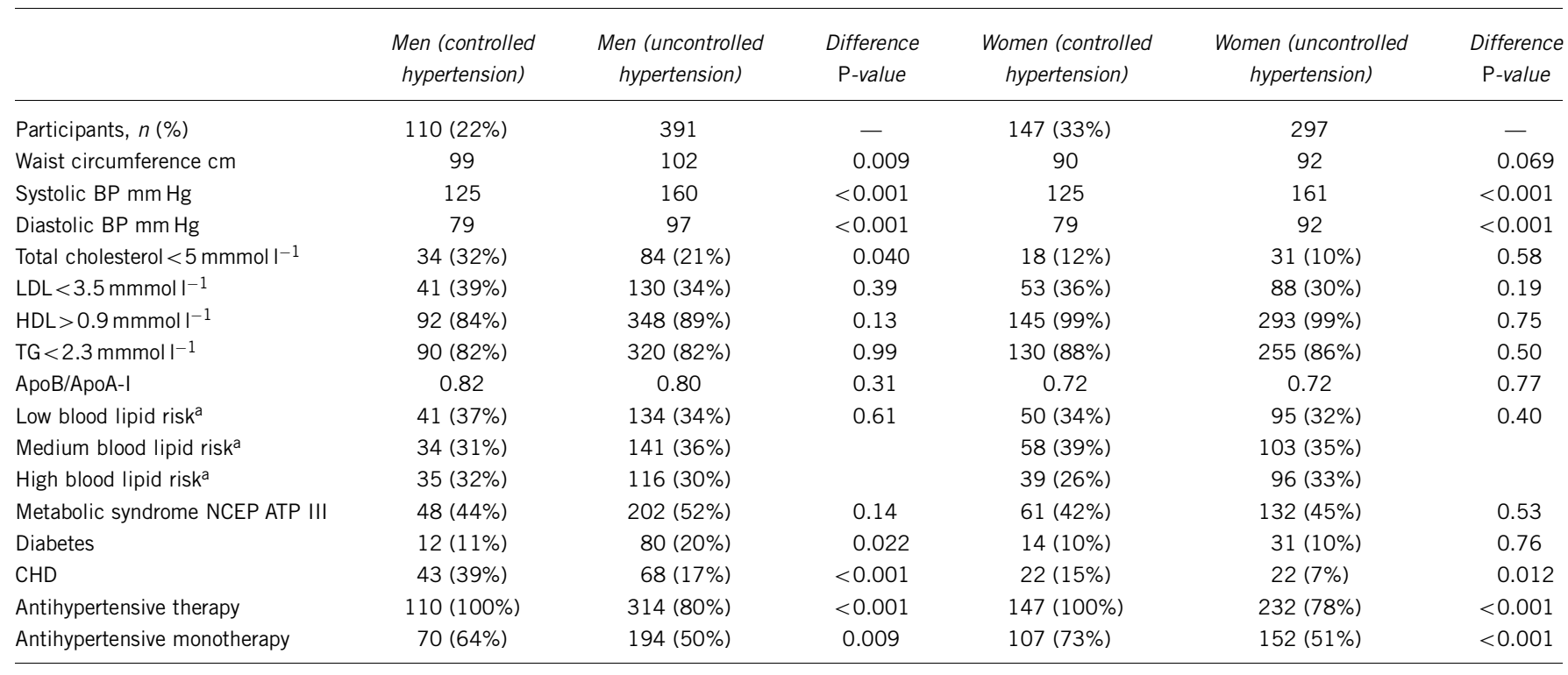

Abbreviations: Apo/ApoA-I, apolipoprotein ratio; BMI, body mass index; BP, blood pressure; LDL, low-density lipoprotein; HDL; high-density lipoprotein; TG, triglyceride; CHD, coronary heart disease. a Low, medium and high blood lipid risk is based on the cutoff levels of the apolipoprotein ratio.

Table 4 Lifestyle and socioeconomic characteristics; differences between participants with controlled hypertension and participants with uncontrolled hypertension, in men and women with diagnosed hypertension

\begin{tabular}{|c|c|c|c|c|c|c|}
\hline$n(\%)$ & $\begin{array}{c}\text { Men (controlled } \\
\text { hypertension) }\end{array}$ & $\begin{array}{l}\text { Men (uncontrolled } \\
\text { hypertension) }\end{array}$ & $\begin{array}{l}\text { Difference } \\
\text { P-value }\end{array}$ & $\begin{array}{c}\text { Women } \\
\text { (controlled hypertension) }\end{array}$ & $\begin{array}{c}\text { Women } \\
\text { (uncontrolled hypertension) }\end{array}$ & $\begin{array}{c}\text { Difference } \\
\text { P-value }\end{array}$ \\
\hline Married/cohabiting & $69(66 \%)$ & $277(73 \%)$ & 0.15 & $34(76 \%)$ & $212(75 \%)$ & 0.74 \\
\hline Living in an apartment & $49(45 \%)$ & $185(50 \%)$ & 0.34 & $92(67 \%)$ & $153(54 \%)$ & 0.012 \\
\hline Employment & $71(65 \%)$ & $254(65 \%)$ & 0.99 & $72(50 \%)$ & $178(60 \%)$ & 0.029 \\
\hline Education & & & 0.15 & & & 0.24 \\
\hline Low & $62(56 \%)$ & $236(61 \%)$ & & $85(59 \%)$ & $198(67 \%)$ & \\
\hline Intermediate & $24(22 \%)$ & 55 (14\%) & & $20(14 \%)$ & 29 (10\%) & \\
\hline High & $24(22 \%)$ & $96(25 \%)$ & & $39(27 \%)$ & $70(24 \%)$ & \\
\hline Financially satisfied & $88(80 \%)$ & $278(72 \%)$ & 0.080 & $95(66 \%)$ & $204(69 \%)$ & 0.47 \\
\hline No health care for financial reasons & $6(6 \%)$ & $46(12 \%)$ & 0.060 & $25(17 \%)$ & 35 (12\%) & 0.13 \\
\hline Smoking & & & 0.84 & & & 0.17 \\
\hline Never & $38(35 \%)$ & $126(32 \%)$ & & $73(50 \%)$ & 125 (42\%) & \\
\hline Current & $18(16 \%)$ & $72(18 \%)$ & & $33(22 \%)$ & $63(21 \%)$ & \\
\hline Former & $54(49 \%)$ & $192(49 \%)$ & & $41(28 \%)$ & 109 (37\%) & \\
\hline Total alcohol $\geqslant 30$ g per day & $17(15 \%)$ & $89(23 \%)$ & 0.097 & $9(6 \%)$ & $16(5 \%)$ & 0.75 \\
\hline Regular physical activity & $39(36 \%)$ & $114(30 \%)$ & 0.19 & $38(27 \%)$ & $62(21 \%)$ & 0.24 \\
\hline Weekly intake of oily fish & $84(76 \%)$ & $283(72 \%)$ & 0.47 & $31(21 \%)$ & $83(28 \%)$ & 0.12 \\
\hline Weekly intake of non-oily fish & $38(35 \%)$ & $121(31 \%)$ & 0.47 & $102(69 \%)$ & $203(69 \%)$ & 0.86 \\
\hline Weekly intake of sausage or bacon & $69(63 \%)$ & $202(52 \%)$ & 0.042 & 57 (39\%) & 89 (30\%) & 0.063 \\
\hline Weekly intake of fried potatoes & $49(45 \%)$ & $167(43 \%)$ & 0.75 & $29(20 \%)$ & $56(19 \%)$ & 0.83 \\
\hline Weekly intake of $>4$ eggs & $98(89 \%)$ & $329(84 \%)$ & 0.20 & $11(7 \%)$ & 27 (9\%) & 0.57 \\
\hline Daily intake of fruit & $71(65 \%)$ & $204(52 \%)$ & 0.021 & $112(76 \%)$ & 229 (77\%) & 0.83 \\
\hline Daily intake of vegetables & $67(61 \%)$ & $221(56 \%)$ & 0.41 & $93(63 \%)$ & $216(73 \%)$ & 0.041 \\
\hline
\end{tabular}

With regard to monotherapy, this was associated with controlled hypertension in both men and women and may be explained by the fact that some individuals respond well to the first prescribed drug. Individuals on antihypertensive polytherapy (more than one drug) are more likely to be therapy resistant. In a study over 2 years, of hypertensive veterans in New England, patients on intensive therapy had better blood pressure control, and the authors concluded that many physicians are not treating hypertension aggressively enough. ${ }^{23}$ In contrast to that study and in agreement with our findings, more antihypertensive drugs have been associated with poor control, ${ }^{10}$ 
indicating that hypertension seems difficult to treat, when initial treatment fails.

Despite previous studies showing that blood pressure is lowered with a change of diet and exercise, ${ }^{24,25}$ all individuals with controlled hypertension had antihypertensive drug therapy. Perhaps lifestyle changes are more important for the primary prevention of hypertension $^{26}$ and for an improvement of metabolic health. ${ }^{27} \mathrm{~A}$ more aggressive antihypertensive treatment of hypertension is also warranted, as a reduction in blood pressure beyond $140 / 90 \mathrm{~mm} \mathrm{Hg}$ leads to lower mortality and cardiovascular event rates. ${ }^{2}$

Coronary heart disease was significantly and negatively associated with uncontrolled hypertension in both men and women. Individuals with $\mathrm{CHD}$ are likely to be treated more intensively and may have received $\beta$-blockers and possibly angiotensin-converting enzyme inhibitors as secondary prevention. ${ }^{28}$ Besides, medication adherence is probably higher in individuals who have suffered a serious cardiovascular event or because of symptom relief of angina pectoris.

A large waist circumference was associated with uncontrolled hypertension. This may be explained by the strong linkage that obesity has to hypertension. ${ }^{29}$ However, it could be that obese individuals are less successful in complying with lifestyle advice. Daily fruit intake was associated with having a goal blood pressure in hypertensive men, which may be explained by the high potassium and soluble fiber content in fruit and its beneficial effects on blood pressure in hypertensive individuals. ${ }^{24}$ Another explanation may be that eating fruit daily is associated with an overall healthy lifestyle.

On the basis of a previous study of newly diagnosed high blood pressure, we expected higher educational level to be associated with controlled hypertension. ${ }^{7}$ Surprisingly, this was not the case. We found that strengths of the cohort were firstly that it was representative and population-based, which is quite rare in hypertension control studies, including one-third of all 60-year-old men and women in Stockholm County. Age, which we do not have to adjust for with this design, is of major importance for cardiovascular risk, especially in women. ${ }^{1}$ Only people with previously diagnosed hypertension and/or antihypertensive drug treatment were included, making the studied population more homogenous. There was a high total response rate of $77 \%$. The good quality of Swedish population registers, allowing us to reach the whole population, and thus ensuring a good representation, also adds certainty to our results.

The study also has some limitations. In cross-sectional studies, none of the observed associations can be interpreted as causal. The findings of this study may only be valid for 60 -year-olds, as metabolic factors vary greatly with age and age adjustments may introduce bias. The baseline investigation was not primarily designed to study blood pressure control; however, its thoroughness enabled us to analyze several unique variables. Salt intake is highly important for blood pressure, and regrettably, our baseline investigation lacks reliable data on it.

\section{CONCLUSIONS}

A total of $78 \%$ of men and $67 \%$ of women with diagnosed hypertension did not reach goal blood pressure. In addition, many had signs of metabolic syndrome and also dyslipidemia. Many differences exist between men and women in factors associated with hypertension control. For example, daily fruit intake was of importance among men and living in an apartment among women.

Thus, more efforts are warranted to reduce blood pressure and modulate associated risk factors to be able to reduce the high morbidity and mortality seen in individuals with hypertension. Where possible, gender differences need to be accounted for.

\section{CONFLICT OF INTEREST}

The authors declare no conflict of interest.

\section{ACKNOWLEDGEMENTS}

The study was supported by unconditional grants from the Stockholm County Council, Karolinska Institutet, the Swedish Heart and Lung Foundation, the Swedish Council for Working Life and Social Research, the Swedish Research Council (Longitudinal Research and K2005-27X-14278-04A).

1 Mancia G, De Backer G, Dominiczak A, Cifkova R, Fagard R, Germano G, Grassi G, Heagerty AM, Kjeldsen SE, Laurent S, Narkiewicz K, Ruilope L, Rynkiewicz A, Schmieder RE, Struijker Boudier HA, Zanchetti A, Vahanian A, Camm J, De Caterina R, Dean V, Dickstein K, Filippatos G, Funck-Brentano C, Hellemans I, Kristensen SD, McGregor K, Sechtem U, Silber S, Tendera M, Widimsky P, Zamorano JL, Kjeldsen SE, Erdine S, Narkiewicz K, Kiowski W, Agabiti-Rosei E, Ambrosioni E, Cifkova R, Dominiczak A, Fagard R, Heagerty AM, Laurent S, Lindholm LH, Mancia G, Manolis A, Nilsson PM, Redon J, Schmieder RE, Struijker-Boudier HA, Viigimaa M, Filippatos G, Adamopoulos S, Agabiti-Rosei E, Ambrosioni E, Bertomeu V, Clement D, Erdine S, Farsang C, Gaita D, Kiowski W, Lip G, Mallion JM, Manolis AJ, Nilsson PM, O'Brien E, Ponikowski P, Redon J, Ruschitzka F, Tamargo J, van Zwieten P, Viigimaa M, Waeber B, Williams B, Zamorano JL. 2007 Guidelines for the management of arterial hypertension: The Task Force for the Management of Arterial Hypertension of the European Society of Hypertension (ESH) and of the European Society of Cardiology (ESC). Eur Heart J 2007; 28: 1462-1536.

2 Turnbull F. Effects of different blood-pressure-lowering regimens on major cardiovascular events: results of prospectively-designed overviews of randomised trials. Lancet 2003; 362: 1527-1535.

3 Persson M, Carlberg B, Mjorndal T, Asplund K, Bohlin J, Lindholm L. 1999 WHO/ISH Guidelines applied to a 1999 MONICA sample from northern Sweden. J Hypertens 2002; 20: 29-35.

4 Weinehall L, Ohgren B, Persson M, Stegmayr B, Boman K, Hallmans G, Lindholm LH. High remaining risk in poorly treated hypertension: the 'rule of halves' still exists. $J$ Hypertens 2002; 20: 2081-2088.

5 Volpe M, Tocci G, Trimarco B, Rosei EA, Borghi C, Ambrosioni E, Menotti A, Zanchetti A, Mancia G. Blood pressure control in Italy: results of recent surveys on hypertension. J Hypertens 2007; 25: 1491-1498.

6 Wolf-Maier K, Cooper RS, Kramer H, Banegas JR, Giampaoli S, Joffres MR, Poulter N, Primatesta $P$, Stegmayr B. Thamm M. Hypertension treatment and control in five European countries, Canada, and the United States. Hypertension 2004; 43: 10-17.

7 Carlsson AC, Wandell PE, de Faire U, Hellenius ML. Risk factors associated with newly diagnosed high blood pressure in men and women. Am J Hypertens 2008; 21: 771-777.

8 Ong KL, Tso AW, Lam KS, Cheung BM. Gender difference in blood pressure control and cardiovascular risk factors in Americans with diagnosed hypertension. Hypertension 2008; 51: 1142-1148.

9 Li C, Engstrom G, Hedblad B, Janzon L. Sex-specific cardiovascular morbidity and mortality in a cohort treated for hypertension. J Hypertens 2006; 24: 1523-1529.

10 Arcucci O, de Simone G, Izzo R, Rozza F, Chinali M, Rao MA, Bodenizza C, De Luca N, Trimarco B. Association of suboptimal blood pressure control with body size and metabolic abnormalities. J Hypertens 2007; 25: 2296-2300.

11 Carlsson AC, Wandell PE, de Faire U, Hellenius ML. Prevalence of hypertension in immigrants and Swedish-born individuals, a cross-sectional study of 60-year-old men and women in Sweden. J Hypertens 2008; 26: 2295-2302.

12 Carlsson AC, Wandell PE, Halldin M, de Faire U, Hellenius ML. Is a unified definition of metabolic syndrome needed? Comparison of three definitions of metabolic syndrome in 60-year-old men and women. Metab Syndr Relat Disord 2009; 7: 231-241.

13 Wandell PE, de Faire U, Hellenius ML. High intake of alcohol is associated with newly diagnosed diabetes in 60 years old men and women. Nutr Metab Cardiovasc Dis 2007; 17: 598-608.

14 Grundy SM, Cleeman JI, Daniels SR, Donato KA, Eckel RH, Franklin BA, Gordon DJ, Krauss RM, Savage PJ, Smith Jr SC, Spertus JA, Costa F. American Heart A, National Heart LaBI. Diagnosis and management of the metabolic syndrome: an American Heart Association/National Heart, Lung, and Blood Institute Scientific Statement. [erratum appears in Circulation. 2005 Oct 25;112(17):e297]. Circulation 2005; 112: 2735-2752.

15 Walldius G, Jungner I. The apoB/apoA-I ratio: a strong, new risk factor for cardiovascular disease and a target for lipid-lowering therapy - a review of the evidence. J Intern Med 2006; 259: 493-519.

16 McQueen MJ, Hawken S, Wang X, Ounpuu S, Sniderman A, Probstfield J, Steyn K, Sanderson JE, Hasani M, Volkova E, Kazmi K, Yusuf S. Lipids, lipoproteins, and apolipoproteins as risk markers of myocardial infarction in 52 countries (the INTERHEART study): a case-control study. Lancet 2008; 372: 224-233. 
17 Sierra-Johnson J, Fisher RM, Romero-Corral A, Somers VK, Lopez-Jimenez F, Ohrvik J, Walldius G, Hellenius ML, Hamsten A. Concentration of apolipoprotein B is comparable with the apolipoprotein B/apolipoprotein $\mathrm{A}-\mathrm{I}$ ratio and better than routine clinical lipid measurements in predicting coronary heart disease mortality: findings from a multiethnic US population. Eur Heart J 2009; 30: 710-717.

18 Cederholm J, Nilsson PM, Anderberg CP, Froberg L, Petersson U. Blood pressure and other cardiovascular risk factors among treated hypertensives in Swedish primary health care. Scand J Prim Health Care 2002; 20: 224-229.

$19 \mathrm{Gu} \mathrm{Q}$, Burt VL, Paulose-Ram R, Dillon CF. Gender differences in hypertension treatment, drug utilization patterns, and blood pressure control among US adults with hypertension: data from the National Health and Nutrition Examination Survey 1999-2004. Am J Hypertens 2008; 21: 789-798.

20 Franklin SS, Pio JR, Wong ND, Larson MG, Leip EP, Vasan RS, Levy D. Predictors of new-onset diastolic and systolic hypertension: the Framingham Heart Study. Circulation 2005; 111: 1121-1127.

21 Gu D, Wildman RP, Wu X, Reynolds K, Huang J, Chen CS, He J. Incidence and predictors of hypertension over 8 years among Chinese men and women. $J$ Hypertens 2007; 25: 517-523
22 D'Amore S, Mora S. Gender-specific prediction of cardiac disease: importance of risk factors and exercise variables. Cardiol Rev 2006; 14: 281-285.

23 Berlowitz DR, Ash AS, Hickey EC, Friedman RH, Glickman M, Kader B, Moskowitz MA. Inadequate management of blood pressure in a hypertensive population. $N$ Eng/ J Med 1998; 339: 1957-1963.

24 Craddick SR, EImer PJ, Obarzanek E, Vollmer WM, Svetkey LP, Swain MC. The DASH diet and blood pressure. Curr Atheroscler Rep 2003; 5: 484-491.

25 Whelton SP, Chin A, Xin X, He J. Effect of aerobic exercise on blood pressure: a meta-analysis of randomized, controlled trials. Ann Intern Med 2002; 136: 493-503.

26 Whelton PK, He J, Appel LJ, Cutler JA, Havas S, Kotchen TA, Roccella EJ, Stout R, Vallbona C, Winston MC, Karimbakas J. Primary prevention of hypertension: clinical and public health advisory from The National High Blood Pressure Education Program. JAMA 2002; 288: 1882-1888.

27 Halldin M, Rosell M, de Faire U, Hellenius ML. The metabolic syndrome: prevalence and association to leisure-time and work-related physical activity in 60-year-old men and women. Nutr Metab Cardiovasc Dis 2007; 17: 349-357.

28 Kahan T, Wandell P. Risk factors in established coronary heart disease: evaluation of a secondary prevention programme. J Cardiovasc Risk 2001; 8: 73-80.

29 Haslam DW, James WP. Obesity. Lancet 2005; 366: 1197-1209. 